\title{
La crueldad y otras dimensiones de excepcionalidad en discursos sobre hechos de violencia
}

\author{
Marcela Perelman \\ Universidad de Buenos Aires (UBA)
}

La crueldad y otras dimensiones de excepcionalidad en discursos sobre hechos de violencia

Resumen: Este trabajo presenta una indagación sobre los conceptos presupuestos sobre la violencia en discursos en circulación, a partir del análisis de discursos sobre el homicidio de una joven embarazada por parte de un funcionario policial en un barrio popular de Buenos Aires, Argentina ${ }^{1}$. Se analizan marcas textuales que permiten acceder a sentidos expuestos y supuestos en torno del concepto de violencia, con especial atención a los aspectos que aparecen como indicaciones de una violencia del más alto grado. Poner luz sobre aquello que es señalado como exceso, como excepción, puede aportar a la comprensión de lo que es considerado normalmente como violencia.

Palabras clave: violencia, crueldad, discurso, excepción, policía.

\section{A crueldade e outras dimensões de excepcionalidade em discursos sobre fatos violentos}

Resumo: Este trabalho apresenta uma indagação sobre os conceitos pressupostos a respeito de violência nos discursos em circulação. Tem como ponto de partida a análise de discursos sobre o homicídio de uma jovem grávida cometido por um funcionário policial em um bairro popular de Buenos Aires (Argentina). São analisadas marcas textuais que permitem acessar a sentidos expostos e supostos em torno do conceito de violência, com especial atenção aos aspectos que aparecem como indicações de uma violência do mais alto grau. Iluminar sobre aquilo que é assinalado como excesso, como exceção, pode aportar à compreensão do que é considerado normalmente como violência.

Palavras-chave: violência, crueldade, discurso, exceção, polícia.

\section{Cruelty and Other Dimensions of Exceptionality in Discourses about Violent Acts}

Abstract: This study analyzes concepts related to violence in discourses in circulation. It is based on an analysis of discourses about the homicide of a pregnant young woman committed by the staff member of a police department in a poor neighborhood of Buenos Aires, Argentina. The textual marks that allow accessing the meanings exposed and supported around the concept of violence are analyzed. Special attention is given to the factors that appear as indications of a violent act of greater degree. Revealing that which is considered excessive, with exception, can help in the understand of that which is normally considered as violence.

Key words: violence, cruelty, discourse, exception, police. 


\section{Introducción}

La palabra y el concepto de 'violencia' son motivos recurrentes de debates teóricos y filosóficos ${ }^{2}$, especialmente en relación con la violencia política o con la violencia y la política. Sus límites con otras nociones como poder, crueldad, fuerza son permanentemente discutidos. Qué es la violencia, de qué hablamos cuando hablamos de violencia, son planteos ya clásicos y aun no zanjados en la discusión filosófica. Por el contrario, el uso frecuente de la palabra 'violencia' en diversos discursos en circulación no parece ser motivo de igual reflexión:

Una de las primeras cosas que debiéramos tratar de entender es la compleja polisemia del concepto 'violencia' en sus usos sociales, para poner en foco discusiones que, hablando de muchas cosas a la vez, tornan dificultoso arribar a consensos provisionales sobre puntos particulares (BRIONES, 2003, p. 6). por parte de un funcionario policial en Villa Lugano (ciudad de Buenos Aires, Argentina) el $1^{\circ}$ de abril de 2005. Se seleccionaron 50 notas publicadas tanto en los días siguientes a la muerte, como al momento de los juicios orales; principalmente de los diarios nacionales, pero también de algunos medios independientes.

No hay una intención de establecer un análisis empírico o psicológico de la naturaleza de las acciones, procuramos "[...] evitar toda perspectiva empirista de la enunciación" (VERON, 1987, p. 16). Por el contrario, rastreamos en los textos marcas que permitan acercarnos a los sentidos expuestos y supuestos en torno del concepto de violencia.

El asesinato de Camila Arjona, de 14 años y con cuatro meses de embarazo, deja ver el tipo de relaciones particularmente violentas que la policía mantiene con ciertos sectores, como los jóvenes pobres, como quienes viven en las villas de emergencia:
Los reiterados debates en torno de la justificación, la legalidad o la legitimación de la violencia no parecen derivar en controversias respecto al concepto o a la calificación de un hecho como violento. La calificación de un hecho como 'violento' permanece en un nivel descriptivo, crudo, de los hechos y no al nivel de las interpretaciones sujetas a mayores controversias.

Este es uno de los motivos que me orientan a indagar en el concepto supuesto de violencia, que al no ser objeto de debates podría incluirse en lo que Teun van Dijk (2003, p. 22) denomina common ground o fundamento común:

\begin{abstract}
Existe un enorme cuerpo de conocimiento que nunca se cuestiona y que aceptan todos los miembros potencialmente competentes de una cultura [...]. Son los tipos de creencias que la gente presupone en la interacción y el discurso diarios.
\end{abstract}

\section{Perspectivas metodológicas}

El análisis de los sentidos presupuestos o implicados puede ayudar a reponer aspectos de la definición de violencia en uso. La propuesta de este trabajo es un análisis discursivo de textos sobre un hecho de violencia: el homicidio de Camila Arjona,
En la madrugada del $1^{\circ}$ de abril de 2005, un policía custodiaba un negocio en el barrio de Lugano, de la Ciudad de Buenos Aires, acompañado por otros dos funcionarios policiales, quienes se encontraban francos de servicio. Ninguno de los funcionarios vestía uniforme.

Según testigos del hecho, los funcionarios habían estado bebiendo cerveza en el almacén que vigilaban y se acercaron a un grupo de jóvenes que estaba reunido en una esquina. De acuerdo con las declaraciones de uno de los jóvenes, los policías se les acercaron para pedirle a uno de ellos que fuera a comprar cocaína. El joven se negó y lo golpearon brutalmente contra un poste de luz hasta que le hicieron perder un diente.

Según las fuentes consultadas, en medio de la agresión alguien disparó un arma. No está claro quién fue, pero se presume que pudo haberlo hecho un vecino que, al ver que golpeaban al joven, disparó al aire con el objeto de disuadir a quienes, a los ojos de cualquier testigo casual, eran tres civiles armados. Al escuchar la detonación, los tres funcionarios dispararon sus armas reglamentarias. Según un vecino que se encontraba en el techo de su casa, dos de los policías tiraban al aire y otro disparaba al grupo de jóvenes que se encontraba en la esquina. Camila y su novio, Leo, se encontraban durmiendo cuando se despertaron por los ruidos y salieron a la 
calle para ver qué ocurría y cerciorarse que el hermano de Leo, quien no había regresado a su casa, estuviera bien. Cuando salieron, los policías les dieron la voz de alto. Leo no obedeció y volvió corriendo a su casa. Camila obedeció y, acto seguido, recibió un balazo en la espalda y otro en la cabeza, cayendo al piso herida de muerte. Según testigos, uno de los efectivos se acercó al cuerpo de la joven, le levantó la cabeza agarrándola del pelo y luego la pateó en la cara. Según los peritajes, Camila murió por haber recibido dos tiros por la espalda disparados a menos de cinco metros de distancia (CENTRO DE ESTUDIOS LEGALES Y SOCIALES, 2005, p. 242-243).

Centralmente, hay un rasgo que estuvo presente en la cobertura mediática que me orientó a analizar este caso, entre otros cuyo tratamiento los ha señalado como hechos extremos, casos que van 'más allá':

Ni ese caso [el del asesinato de Ezequiel Demonty] ni el de Camila se encuadran directamente en lo que se conoce como gatillo fácil. No se trata de situaciones dudosas en las que un arma policial es disparada con ligereza. No se trata de tener el gatillo aceitado, ni siquiera de no manejar ni con prudencia ni con responsabilidad ese gatillo. En ambos casos hay odio. Un odio inexplicable, reconcentrado. [...] En todos esos casos hubo violencia policial y asesinatos, pero además hubo constancia de una crueldad que excede cualquier tipología que describa a 'las personas' (RUSSO, 2005, las comillas son originales del texto).

Otra crónica, bajo el titulo "La Villa 20, antes y después de Camila”, señala: “En un barrio acostumbrado a los excesos policiales, los vecinos se sorprenden por la irracionalidad" y se citan los testimonios de la madre de la víctima y de otros testigos:

'Que te agarren, que te peguen, siempre pasa. Que la policía le pegue a alguno que robó. Que les tire a los que ellos dicen que robaron. Pero que hayan matado a Camila como lo hicieron, es increíble', musita Norma Díaz, con la foto de su hija en la mano (CAPPIELLO, 2005c).

En el centro de Salud comparten la sensación de Luz. 'Están los que transan con la policía y los que son sus víctimas. Es habitual que haya disparos, heridos, muertos, pero por ajustes de cuentas entre pandillas o porque un policía les pegó. Pero lo que pasó con Camila cambió todo en el barrio, se sinceran allí (CAPPIELLO, 2005c).

¿Cuáles son los aspectos que aparecen como indicaciones de una violencia del más alto grado, 'increíble', 'de una crueldad que excede cualquier tipología que describa a las personas'? Como hemos visto, no se trata de indagar en la excepcionalidad de los hechos, sino en aquellos rasgos que son destacados en las noticias para señalar grados máximos de violencia. Considero que poner luz sobre aquello que es señalado como exceso, como excepción, puede aportar a la comprensión de lo que es considerado 'normalmente' como violencia.

\section{Noticia / relato / narrativa}

Hasta aquí las referencias a los textos escogidos han sido muy genéricas como notas periodísticas, noticias o crónicas. He querido preservar este nivel de generalidad para problematizar ahora su denominación como objetos de análisis. Las teorías sobre narrativa y argumento pueden también aportarnos pistas acerca del contenido, supuesto y expuesto, de los textos.

La diferenciación paradigmática entre argumentación y narrativa corresponde a muy arraigadas tradiciones. Mientras que la narrativa "[...] se manifiesta en el cuento [...], el mito, la ficción novelezca", la racionalidad argumentativa "[...] se expresa de manera privilegiada en otro tipo de discursos, como el discurso filosófico, científico y aun didáctico y político.” Mientras que, esquemáticamente, se postula que el "acto de contar es más autentico, más moral", frecuentemente relegado a los discursos del "arte y la literatura, los de los niños o los inventores iluminados"; en oposición, "la racionalidad argumentativa parece de una naturaleza totalmente diferente", requiere el dominio de una lógica, debe ser racional, razonable y usar demostraciones, pruebas (PARRET, 1995, p. 55-57).

Lo argumental y lo narrativo conviven en los textos periodísticos que analizamos. En los textos se encuentran “zonas más descriptivas” (VERÓN, 1987, p. 20), ligadas a un discurso periodístico, de sección policial, sobre hechos que serán materia judicial, que ya reciben tratamiento de 'casos'. Se trata de textos en los que se va probando (con argumentos, con fotografías, con testimonios) que los hechos ocurrieron y las personas actuaron de determinadas formas. Sin embargo, en los diferentes artículos, también se encuentran secuencias narrativas, relatos acerca de cómo fue que ocurrieron los hechos, en los que se repone la subjetividad de los 'actores', incluso de las víctimas. Relatos 'extra-fotográficos' que no pueden referir a las pruebas aportadas, aunque se apoyen en ellas:

Camila, luego de escuchar los tiros de la policía, que se produjeron al escapar el grupo de chicos al que les habían pedido que vayan a comprar droga, 
se preocupó por su novio que había salido de la casa y fue a ver cómo estaba [...] (LA FOGATA, 2005, online).

Este cruce entre la argumentación y la narración está presente permanentemente en los textos analizados. No es, sin embargo, un rasgo anómalo o atípico. La paradigmatización que opone narratividad a argumentación ha sido fuertemente discutida por Parret, quien propone homologaciones y plantea 'constelaciones' de cómo se presentan los cruces entre estos registros. La presencia de 'narraciones' en los artículos tiene diferentes funciones argumentales. En primer lugar, para ilustrar un argumento, pero también porque su inclusión tiene, en sí misma, valor argumentativo, "[...] reemplaza un argumento o a una secuencia del argumento", ya que "el cuento tiene valor de argumento y su fuerza argumentativa es superior a la de un razonamiento abstracto" (PARRET, 1995, p. 72).

Al contrario de lo que se podría suponer, que lo argumentativo tiene una carga referencial mayor o una verosimilitud superior a la narración, White (1992, p. 20-21) entiende la narración como "[...] forma de representación de los acontecimientos que se conceptúan reales en vez de imaginarios." Lejos de dotar de un aspecto ficcional a los acontecimientos, la narrativa aporta una impresión de objetividad, dado que aparecen borradas las marcas de subjetividad propias de la enunciación discursiva (aquellas que refieren al 'yo' que mantiene el discurso: deícticos como pronombres, adverbios, etc). En la narrativa "no habla nadie" (WHITE, 1992, p. 19).

A continuación vemos la inclusión de una narrativa en el marco de un discurso argumentativo:

Hay un plus de desprecio, de vileza, de instinto asesino que a esta altura no tiene nada de extraño y que corona este caso con la más escalofriante de las posibles descripciones: 'Camila ya caída, muerta, en el pasillo. Uno de los policías se acerca a ella. Le levanta la cabeza tirándole del pelo. Le patea la cara varias veces, con saña, hasta provocarle un hematoma que después fue fotografiado por la familia de la víctima. El policía parece tenerle rabia a la chica muerta. Parece querer infligirle, además de la muerte, algún tipo de lección’. Esas patadas en la cara de una chica embarazada, inerme, esas patadas para rematarla, ¿en qué palabras caben? ¿En qué tipo de maldad caben? ¿En qué bolsón ancestral de rencor, en qué voluntad consciente o inconsciente de venganza caben? (RUSSO, 2005, el destacado entre comillas simples es de la autora y señala el pasaje narrativo).

¿Cuál es el o los 'argumentos' que reemplazan la narrativa? Este pasaje narrativo tiene un lugar clave en el argumento general, es la secuencia de acciones que incluye "la más escalofriante de las posibles descripciones", hay aspectos de esta secuencia que permiten argumentar que la acción policial que se narra excede las palabras y el concepto de maldad. Es en esta narrativa que se cuenta el hecho que marca que la definición de violencia - supuesta en el mismo texto - ha sido superada. Como la narración comienza con "Camila ya muerta", sabemos que no es la muerte lo que supera el concepto de violencia. Lo que ha quedado fuera de escala de la violencia es el hecho de que el policía "Le patea la cara varias veces, con saña." El texto presenta este hecho como fuera de la escala de la violencia.

Aparecen, en las noticias sobre hechos de violencia analizadas, figuras antitéticas en las que se oponen la muerte y la actitud policial. La oposición de 'actitudes' frente al dolor de los heridos y el respeto a los muertos se presenta como una marca liminar, que opone categorías de sujetos:

[...] Al pasar por el cuerpo de Camila, uno de los policías, se paró frente a la joven asesinada, la tomó por los cabellos, la dio vuelta para mirarle a la cara, diciendo "uy, nos equivocamos", y le pegó un puntapié en medio de la cabeza. A esa altura, Camila ya estaba muerta... (LAFOGATA, 2005, online).

Estas oposiciones antitéticas marcan un límite que separa categorías de sujetos. Es a partir de las acciones que se predican sobre ellos en relación con su acción frente a los cuerpos agonizantes o muertos (llamar o no a una ambulancia, cubrir o no los cuerpos, estar desesperado o sonreír, agredir a los cuerpos muertos) que se establece un límite. Como se plantea en uno de los textos analizados: "[H]ubo constancia de una crueldad que excede cualquier tipología que describa a 'las personas'." Aquello que señalaba Aristóteles (2005, p. 104), que "[...] es un delito más grave el más bestial" tiene completa vigencia. Al predicar ciertas acciones se categoriza al sujeto de la acción como bestial o inhumano: hay un "[...] repertorio desviado de las 'conductas extrañas' de las personas" (RUSSO, 2005) y hay acciones que quedan por fuera de ese repertorio, que "no pertenecen 'al hombre'." Hay acciones violentas consideradas 'humanas' y otras que no. Y esta oposición humanidad-inhumanidad no se apoya sobre lo que podría considerarse como el hecho más grave de la violencia, dar muerte, sino sobre otros rasgos de las acciones.

\section{Escalaridad en la violencia}

Según las teorías de la polifonía y de la argumentación en la lengua, el lenguaje tiene un 
carácter gradual. Estas teorías trasladan las características de los topoi clásicos a las palabras con contenido léxico: "[...] aplicar ciertas palabras a objetos o situaciones es indicar ciertos tipos de discursos posibles a propósito de estos objetos o situaciones" (DUCROT, 1998, p. 47). Es decir, en la medida en que las palabras evocan discursos argumentales tópicos, las palabras actúan como ases tópicos, "[...] la significación de las palabras, dado que está constituida por topoi, conlleva en sí misma un tipo de gradualidad", tienen una gradualidad intrínseca. Según Oswald Ducrot:

[...] admitimos que los topoi pueden, de una manera general, aplicarse con más o menos fuerza: Nos podemos declarar más o menos legitimados para presentar un hecho como una consecuencia o como una excepción; dicho de otro modo, algunos encadenamientos discursivos pueden darse como más o menos necesarios que otros.

Ducrot explica que no se refiere simplemente a que a las palabras "se puedan asociar determinaciones susceptibles de grado", o sea, que 'desde afuera' se les agregue un 'más' o un 'menos', o un modificador del tipo 'lejos' o 'cerca' que exprese externamente diferentes grados de la palabra. Por el contrario, lo que propone es que en la palabra misma se encuentra la gradualidad ("la gradualidad intrínseca de los predicados del lenguaje") y que esta gradualidad se expresa de otras maneras. Es en este contexto que se plantea que los modificadores realizantes y desrealizantes ponen de manifiesto el carácter gradual del lenguaje, de las palabras.

Destacamos que, como se ve en los siguientes ejemplos, los modificadores realizantes admiten incorporar - sin alterar el sentido del argumento expresiones como 'es más', ‘incluso', ‘de hecho' en la oración. Y que los modificadores desrealizantes admiten la incorporación de 'pero' o 'sin embargo'.

Para volver a las temáticas de la violencia, la propuesta es pensar, por ejemplo, que el sustantivo 'violencia' no sólo puede graduarse externamente como en 'La policía actuó con mucha violencia', sino que a través de otros modificadores queda de manifiesto que 'violencia' en sí abarca argumentalmente un espectro de grados posibles. Vemos que la siguiente frase resulta argumentalmente lógica: 'El ministro reconoció la violencia, pero dijo que es un hecho aislado'. Por el contrario, no resulta razonable la siguiente: 'El ministro reconoció la violencia, es más, dijo que es un hecho aislado'. Existe una escalaridad implícita en la palabra violencia que indica que la violencia aislada es menos violencia que la violencia reiterada o sistemática. Según Aristóteles (2005, p. 104), “[...] es más grave la repetición frecuente del mismo delito." Decir que se trata de 'un hecho aislado' desrealiza violencia: "En Argentina las explicaciones de la violencia policial en tanto hechos aislados encuentran todavía un gran eco, tanto en las declaraciones de funcionarios policiales como de responsables políticos" (MARTÍNEZ; EILBAUM, 1999, p. 8). Esta es, por ejemplo, la orientación del argumento institucional de la Policía Federal frente al asesinato de Camila Arjona:

En tanto, esta noche el director general de comisarías de la Policía Federal, Gustavo Ramos, deslindó responsabilidades de la fuerza, al afirmar que 'las personas obran de manera extraña en algún momento' y que 'estas situaciones pertenecen al hombre y no a la institución' (CLARÍN, 2005, las comillas son originales del texto).

\section{[...] el jefe de la Circunscripción V, a la que pertenece la seccional 52a., comisario inspector Roberto Palavecino. Al poner las manos con firmeza sobre el escritorio, se esforzó en destacar que la muerte de Camila es un 'hecho aislado' que, dijo, no afecta a la institución, sino que se trata de las acciones de tres 'inadaptados' que dejaron de ser uniformados y que fueron separados de la fuerza por decisión propia (CAPPIELLO, 2005a, las comillas son originales del texto).}

De forma inversa, resulta argumentalmente razonable la frase: "El operativo policial fue violento, de hecho, se secuestraron vainas de munición de plomo"; y no: "El operativo policial fue violento, pero se secuestraron vainas de munición de plomo." $\mathrm{Pa}$ rece obvio que un operativo en el que se disparan municiones de plomo es más violento que uno en el que no se disparan esas municiones. En este sentido, "El lugar del crimen estaba sembrado de vainas [...]" (RODRÍGUEZ, 2005) actúa como modificador realizante de violencia.

Existe, además, una tercera clase de modificadores realizantes: los surrealizantes o sobrerealizantes (GARCÍA NEGRONI, 1996, p. 4), "[...] estos modificadores tienen, entre otras propiedades semánticas especificas, la de indicar el grado extremo en la gradación del predicado al que se aplican". El uso de la expresión 'y encima' tiene valor de 'sobrerealizante'. Un ejemplo de este uso aparece en uno de los testimonios del juicio por la muerte de Camila Arjona: "Vos agarraste la pistola y le tiraste a la piba. Y encima, le pisaste la cabeza', le recriminó Paniagua a Bustos durante el juicio" (CLARÍN, 2006). Encontramos que se trata de una afirmación de grado extremo que se reitera en el siguiente testimonio: “'Lo que más me revienta es que después fue y le pisó la cabeza', declaró el testigo" (CAPPIELLO, 2005a). 


\section{Violencia instrumental y 'restos inútiles'}

Al revisar las discusiones teóricas y filosóficas sobre la definición de la violencia encontramos algunos elementos que pueden iluminar el análisis de la definición de la violencia 'en uso'. Al analizar el concepto de violencia - especialmente de violencia política o de violencia $y$ política - diferentes autores toman como referencia el concepto alemán Gewalt. Aunque se traduce usualmente como 'violencia', en el significado de Gewalt confluyen y oscilan diversos sentidos. De hecho, en algunos casos es traducido también como 'poder' - Jacques Derrida señala el caso de Gesetzgebende Gewalt, que significa 'Poder Legislativo'-y lo encontramos también traducido como 'fuerza' - como en Höhere Gewalt, que significa 'fuerza mayor'. Derrida (1997, p. 234) asume que el término es intraducible y enfatiza que significa también 'autoridad'o 'legítimo poder'.

Una postura marcadamente diferente tiene Hannah Arendt en On Violence (1970) quien, luego de diferenciar puntualmente poder, fortaleza, fuerza y autoridad, restringe el concepto de violencia en función de sus dos niveles 'instrumentales'. Primero, porque requiere del uso de implementos-instrumentos de violencia, armas. En segundo lugar, es instrumental en relación con una perspectiva teleológica, dado que la considera siempre un medio orientado a un fin: "La violencia es por naturaleza instrumental; como todos los medios, siempre requiere dirección y justificación por parte del fin que persigue" (ARENDT, 1970 , p. 150, traducción de la autora).

Por su parte, Étienne Balibar (1996, p. 108-109) plantea que "[...] para tener en cuenta esa incompletud dialéctica de la Gewalt, nos hace falta un tercer termino $[\ldots]$ ¿Qué tercera noción utilizar?" y propone agregar el componente crueldad: " $\mathrm{La}$ fenomenología de la violencia debe incluir, a la vez que su relación intrínseca con el poder, su relación con la crueldad, que es algo diferente." La crueldad aparece, para Balibar, como un "[...] resto inconvertible o un residuo material de idealidad, inútil, y carente de 'sentido'."

Los planteos de Arendt y de Balibar nos aportan elementos sobre los conceptos supuestos en los discursos analizados. Por un lado, está presente la idea de que la violencia es instrumental, orientada a un fin. En tanto permanece en un plano instrumental, puede explicarse.

Sin embargo, en las descripciones aparecen rasgos de la violencia que zafan de esta lógica, que no encajan en una noción racional-instrumental de los sujetos de la violencia: ¿Para qué patea el policía a Camila si 'ya está muerta'? Estas acciones aparecen en la descripción escindidas del 'grueso' de la violencia, quedan por fuera de la escala de la violencia, como resto cruel, inútil: "[...] 'cuando estaba tirada en el suelo uno se acercó y le pateó la cabeza', dijo la mujer" (CLARÍN, 2005).

En las tres citas que siguen se marca un umbral entre la violencia 'que es habitual' de aquella que aparece como cruel y excepcional. El quiebre aparece en las tres citas con el uso de 'pero' y, en los últimos dos casos, también con el cambio de tiempo verbal:

En todos esos casos hubo violencia policial y asesinatos, pero además hubo constancia de una crueldad que excede cualquier tipología que describa a 'las personas' (RUSSO, 2005).

Que te agarren, que te peguen, siempre pasa. Que la policía le pegue a alguno que robó. Que les tire a los que ellos dicen que robaron. Pero que hayan matado a Camila como lo hicieron, es increíble, musita Norma Díaz, con la foto de su hija en la mano (CAPPIELLO, 2005c).

Están los que transan con la policía y los que son sus víctimas. Es habitual que haya disparos, heridos, muertos, pero por ajustes de cuentas entre pandillas o porque un policía les pegó. Pero lo que pasó con Camila cambió todo en el barrio (CAPPIELLO, 2005c).

La violencia 'habitual' (violencia policial, asesinatos, que te agarren, que te peguen, que le peguen a uno que robo, que les tiren a alguno que la policía dice que robó, transar con la policía, ser víctimas, los disparos, los heridos, los muertos, los ajustes de cuenta) parecen poder explicarse a partir de cierta instrumentalidad, en todo caso es así como trabaja la policía. Sin embargo, se narran los hechos de forma tal que algunos rasgos aparecen como un plus inútil, cruel y, por tanto, inexplicable.

Vemos a continuación tres descripciones del momento en el que el policía Bustos se acerca al cuerpo caído de Camila Arjona:

Camila ya caída, muerta, en el pasillo. Uno de los policías se acerca a ella. Le levanta la cabeza tirándole del pelo. Le patea la cara varias veces, con saña... (RUSSO, 2005).

[...] Bustos se acercó dos veces al cadáver de Camila, que yacía tirado en la calle, apenas asfaltada. En una de esas oportunidades le pisó la cabeza y en otra se la levantó dos veces para asegurarse de que estuviera muerta (CAPPIELLO, 2005b).

[...] encontraron zapatos manchados de sangre en uno de los lockers donde los policías guardan sus pertenencias, probablemente los mismos con que le patearon la cara a Camila luego de dispararle y levantarla de los pelos del piso. ‘ $¡ U y$, nos equivoca- 
mos!', habrían exclamado antes de arremeter a las patadas contra su rostro [...] la 'equivocación' a la que aludieron los policías cuando observaron el rostro agonizante de Camila tenía que ver con otra adolescente de 14 años a la que algunos 'hombres de la fuerza' se la tienen jurada hace rato (SANDÁ, 2005, las comillas son originales del texto).

Si bien no hay contradicciones importantes en cuanto al contenido 'referencial' en las descripciones de los hechos, hay diferencias argumentales importantes, especialmente en relación con el sentido de la acción. En el primero se presenta la acción como irracional. La referencia "con saña" subraya el carácter no instrumental de la acción, ya que el ensañamiento refiere a una "insistencia cruel", de "extremar la crueldad en el daño que se causa" (MOLINER, 2000), de un "enojo ciego" (REAL ACADEMIA ESPAÑOLA, 2001). Este carácter 'irracional' apareció desde el inicio de la cobertura del caso:

Para Camila Estefanía Arjona, todo pasó muy rápido. A los 14 años estaba embarazada de cuatro meses y medio, pero no será madre adolescente. Dos balazos que se presume con vehemencia que fueron policiales, además de irracionales, borraron su vida y la del hijo por nacer (RODRÍGUEZ, 2005, destacado de la autora).

En el segundo y en el tercer texto se ofrecen explicaciones a la acción policial. En el segundo, se 'cierra' la instrumentalidad asignándole a la acción el sentido de "asegurarse de que estuviera muerta". En el tercero, se explica la acción a partir de que los policías querían chequear la identidad de la víctima, bajo la hipótesis de que los policías tenían la intención de matar a otra chica a la que "se la tenían jurada".

Se abren, entonces, tres grados de instrumentalidad diferentes: el de la irracionalidad, el de la racionalidad instrumental $\mathrm{y}$, el que podríamos llamar "instrumentalidad de segundo nivel", en el que la explicación teleológica está ligada a una información adicional a la descripción concreta de los hechos. La racionalidad de la acción se explica, en este segundo nivel, en referencia a datos y hechos que se reponen a la descripción de la escena que resignifica el sentido de las acciones: la policía buscaba a otra chica.

\section{Lo excepcional como umbral}

Al analizar diferentes discursos sobre hechos de violencia hemos ido destacando diferentes marcas que constituyen límites, umbrales que separan personas, acciones, hechos. Hemos encontrado diversas 'dimensiones de excepcionalidad', rasgos marcados como 'extraordinarios' en la descripción de los hechos. Así, encontramos referencias a una 'excepcionalidad histórica' (los hechos se presentan como inéditos, las personas se presentan como aturdidas frente a un hecho sin precedentes) y a una 'excepcionalidad territorial' (los hechos tienen lugar en espacios, territorios que se describen como excepcionales, recortados de la ciudad). Vamos a detenernos, sin embargo, en otras tres dimensiones de excepcionalidad: los rasgos excepcionales sobre los agentes, las víctimas y la intensidad de la violencia.

Excepcionalidad de los agentes. Las referencias respecto de la excepcionalidad de los agentes de la violencia (en este caso, funcionarios policiales), aparecen tanto en los argumentos esgrimidos por los allegados a las víctimas y los medios, como por el discurso oficial institucional. Por un lado, vimos el discurso oficial que presenta a los policías como funcionarios 'marginales', no representativos de la institución. Según Martínez y Eilbaum (1999, p. 8, las comillas son originales del texto): "Esta lectura se caracteriza por presentar a la violencia policial como una desviación individual del ejercicio 'normal y correcto' de la fuerza policial, producto de desórdenes en la personalidad o conductas individuales de los funcionarios policiales."

Por otro lado, habíamos señalado la oposición humanidad-inhumanidad que aparece en diferentes discursos en relación con ciertas actitudes de los agentes. Podemos vislumbrar algunas consecuencias de esta 'bestialización' o categorización de los agentes como inhumanos.

En primer lugar, en tanto la frontera que separa a unos y a otros (personas y no-personas) se fija en ciertas actitudes que se recortan (la patada) más que en la secuencia completa de las acciones violentas, estos argumentos pueden también tener como consecuencia el oscurecimiento de una lógica más amplia de la violencia. La indignación moral parece surgir más del "plus de desprecio" (RUSSO, 2005) que de la lógica amplia de violencia en la que se enmarcan. En segundo lugar, la ‘bestialización' de los agentes de la violencia tiende a exorcizar el mal (BRIONES, 2003, p. 6-7) aislando la acción de los sujetos de su marco social, "lo que predeciblemente conduce a externalizar las responsabilidades." De esta forma, la 'bestialización' funciona socialmente en forma análoga al discurso de las 'manzanas podridas' en las instituciones policiales. Se trata de sendos discursos sobre la 'excepcionalidad' o desviación de los sujetos que oscurece un entendimiento más profundo tanto de las instituciones, como de la sociedad.

Excepcionalidad de las víctimas. Hay diferentes formas en las que las víctimas se presentan como excepcionales. Por un lado, a partir del discurso de los 'familiares' (PITA, 2005) y la presentación de las víctimas como seres excepcionales o ejemplares. Por otro lado, 'la excepcionalidad de las víctimas' apare- 
ce también en el discurso oficial cuando se presenta a una víctima como 'un error', como efecto colateral de prácticas policiales que permanecen incuestionadas y que, como toda práctica profesional, es pasible de cometer errores. Este es el razonamiento detrás de la noción de 'terceros muertos en enfrentamientos' $y$, en forma ya más evidente, de las 'víctimas inocentes'.

Según algunos (pocos) medios, la ‘equivocación' en torno de la muerte de Camila Arjona radicaba en que los policías suponían que habían matado a otra chica. Camila pasa así a ser la 'víctima de excepción', mientras que la víctima 'natural' habría sido una chica con problemas con las drogas y la policía.

Excepcionalidad de los hechos o grados de la violencia. Mientras no existen, ni a partir de regulaciones ni de las prácticas, formas claras de medición y evaluación del recurso a la violencia policial, las referencias a los 'usos excesivos' permanecen en un nivel metafórico dispuesto a inscribir los hechos (a partir de los cuales se argumenta) como un error en el marco de una lógica racional. El 'exceso' aparece como un uso excepcional, un desborde que "pasa más allá de la medida o regla" (REAL ACADEMIA ESPAÑOLA, 2001). Por lo que la denuncia sobre ese 'exceso' pasa a (en)cubrir la legitimación de la violencia que queda, así, naturalizada ${ }^{3}$.

Respecto de las referencias sobre la cualidad de los hechos de violencia, hemos visto que las secuencias a veces aparecen escindidas entre una sub-secuencia considerada como 'violenta' y, otra, difícilmente calificable, entendida como cruel y excesiva. Este corte en la secuencia de las acciones no parece ser arbitrario ya que, como hemos visto, está marcado en los mismos puntos en diferentes relatos. Estos recortes de la secuencia que son destacados como un plus cruel e inaceptable, nos dan pistas importantes acerca de la violencia que ha quedado separada como regular.

Adentrémonos por un momento en ese espacio de crueldad, de violencia excepcional, describamos el plus. Se nos presenta una dimensión excesiva de la violencia, de desborde inútil, ensañada, irracional. Hechos que no entran en las palabras, no entendemos para qué actúan como actúan. Son los actos que 'más nos revientan'. Como si todo (los heridos, la muerte) fuera poco, para colmo, encima, tienen el atrevimiento de cometer esta clase de excesos.
Ahora bien, si ese es el espacio iluminado por la 'crueldad', ¿qué es lo que queda a la sombra? Ha quedado presupuesta una noción de violencia regular, medida, necesaria, instrumental. Acciones a las que estamos acostumbrados, que no llegan a saturar nuestra noción de violencia: "Este enfoque, orientado exclusivamente a reconocer la violencia sólo por sus excesos, no plantea críticas respecto de la habitualidad de su ejercicio, propiciando la justificación del uso de la violencia" (MARTÍNEZ; EILBAUM, 1999, p. 7).

Así es que una descripción de los hechos que escinde parte de la secuencia como violencia (humana, esperable) y otra parte como crueldad (extraordinaria, inhumana, incomprensible) tiene consecuencias argumentales similares a las del discurso de los 'excesos'.

\section{Reflexiones finales}

En cuanto al planteo inicial, respecto de de qué hablamos cuando hablamos de violencia (política), del análisis de las piezas periodísticas surgen indicios importantes acerca de que la definición de violencia presupuesta en estos discursos es instrumental. El umbral parece fijarse en la posibilidad de responder a la pregunta ‘¿para qué?’. Cuando se acaban las respuestas se entra en un espacio de violencia considerada extraordinaria, irracional, cruel ${ }^{5}$.

Hemos visto, además, algunas consecuencias argumentales que, entre otras dimensiones, se desprenden de presuponer una noción de violencia instrumental. El discurso moralizante sobre la crueldad es analogable a aquel de los excesos, de la excepción. Evitar los lugares comunes que conducen a trazar entidades excepcionales (zonas, personas, acciones) resulta complejo, dado que el sentido común parece muy atravesado por la oposición entre lo normal y lo excepcional.

Aquella precisa denuncia popular acerca de que en la última dictadura argentina 'no hubo errores, no hubo excesos, son todos asesinos los milicos del proceso' puso en evidencia la falacia de las descripciones que señalan lo residual o excepcional para ocultar lo estructural y sistemático. Sin embargo, la 'excepcionalidad' es una forma muy generalizada de ordenar y narrar los acontecimientos, y se cuela en los discursos de formas muy variadas. Que- 
da abierta la pregunta acerca de si el 'recurso a la excepción' no se filtra en el discurso, incluso, como un condicionante de la enunciación: contar un hecho como excepcional justifica la enunciación misma. Es un recurso que habilita a quien enuncia a reclamar la atención de su audiencia, sean lectores de diarios o funcionarios del Poder Judicial. Pero este recurso parece tener más de un filo, ya que mientras se reclama la atención hacia lo particular se puede velar la denuncia de lo estructural o general ${ }^{6}$.

Se requiere esquivar lugares comunes. Entender, expresar los hechos de forma tal que no se representen separadamente un grueso de la violencia instrumental y un residuo de crueldad, inútil. Tampoco como niveles materiales opuestos a simbólicos, porque la violencia es material y es simbólica. Las señaladas marcas de la crueldad no son un plus, ni deben entenderse como un exceso o resto pulsional, irracional o inútil. Por el contrario, estos rasgos, gestos, actitudes refuerzan los sentidos de toda la acción violenta, pueden entenderse como una firma, una posdata, un subrayado, una 'instrucción de lectura' del sentido de la violencia.

\section{Referencias}

ARENDT, H. On Violence. In: Crises of the Republic. Nueva York: Harvest, 1970, p. 103-198.

ARISTÓTELES. El arte de la retórica. Buenos Aires: Eudeba, 2005.

BALIBAR, E. Violencias, identidades y civilidad. Para una cultura politica global. Barcelona: Gedisa, 1996.

BRIGGS, C. L. Mediating Infanticed: Theorizing Relations between Narrative and Violence. Cultural Anthropology, v. 22, n. 3, agosto 2007 .

BRIONES, C. La violencia está en los otros. En: ENCUENTRO OPINIÓN PÚBLICA, SENTIDO COMÚN, VIOLENCIA Y DERECHOS HUMANOS, 2003. Buenos Aires, CELS.

CAPPIELLO, H. Admiten la responsabilidad policial en el crimen de Camila, La Nación, 5 abr., 2005a, Información General.

. Prisión preventiva a los tres policías por el crimen de Camila. La Nación, 13 abr. 2005b, Información General.

. La Villa 20, antes y después de Camila. La Nación, Buenos Aires, 17 abr. 2005c. Información General.

CENTRODE ESTUDIOS LEGALES Y SOCIALES (CELS). Informe 2005. Derechos Humanos en Argentina. Buenos Aires: Siglo Veintiuno Editores, 2005.
CLARÍN ¿Les tiraron porque no les quisieron comprar droga?, Buenos Aires, 4 abr. 2005, Policiales.

Perpetua para un policía por el crimen de una chica embarazada. Buenos Aires, 17 abr. 2006, Último momento. Disponible en: $<$ http://www.clarin.com/diario/2006/ 04/17/um/m-01179075.htm>. Acceso en: 8 abr. 2008.

DERRIDA, J. Fuerza de Ley: el fundamento místico de la autoridad. Madrid: Tecnos, 1997.

DUCROT, O. Los modificadores desrealizantes. Signo \& Seña, Revista del Instituto de Lingüística, n. 9, p. 45-72, Universidad de Buenos Aires, 1998.

GARCÍA NEGRONI, M. M. Prosodia y Polifonía. El acento de intensidad como marca de la subjetividad del locutor. In: VI CONGRESO NACIONAL DE LA SOCIEDAD ARGENTINA DE LINGÜÍSTICA 'LA ORALIDAD’, 1996. Anais... Tucumán, Universidad Nacional de S. M. de Tucumán, 1996.

LA FOGATA DIGITAL. Policía de comisaría $n$. 52: asesinatos, golpes y amenazas. Buenos Aires, 16 dic. 2005. Disponible en: < http://www.lafogata.org/05arg/arg12/ arg_16-15.htm>. Último acceso en: 8 abr. 2008.

MARTÍNEZ, J.; EILBAUM, L. La violencia policial en Argentina. Un debate sobre las visiones del problema y las políticas posibles. En: PROYECTO POLICÍA Y SOCIEDAD DEMOCRÁTICA. Centro de Estudios Legales y Sociales (CELS, Argentina), Viva Río-ISER (Brasil) y el Instituto de Defensa Legal (Perú), coordinados por el Centro de Estudios para el Desarrollo (CED, Chile), 1999.

MOLINER, M. Diccionario de uso del español. Edición abreviada, Barcelona: Gredos, 2000.

PARRET, H. De la semiótica a la estética. Enunciación, sensación, pasiones. Buenos Aires: Edicial, 1995.

PERELMAN, M. Algunas definiciones sobre la violencia: usos y teorías. In: VII JORNADAS DE SOCIOLOGÍA, 2007, Buenos Aires. Anais..., Buenos Aires, Universidad de Buenos Aires, 2007.

PITA, M. V. Mundos morales divergentes. Los sentidos de la categoría de familiar en las demandas de justicia ante casos de violencia policial. In: TISCORNIA, S.; PITA, M. V. (Comp.). Derechos humanos, tribunales y policías en Argentina y Brasil, Buenos Aires: Antropofagia, 2005.

REAL ACADEMIA ESPAÑOLA. Diccionario de la lengua española. Ed. 23. Mexico: Espasa Calpe, 2001.

RODRÍGUEZ, C. Una nena víctima de balas policiales. Página/12, Buenos Aires, 2 abr. 2005. Sociedad. 
RUSSO, S. Camila, Ezequiel, Darío, Maximiliano. Página/ 12, Buenos Aires, 16 abr. 2005. Contratapa.

SANDÁ, R. El horizonte de un día. Página/12, Buenos Aires, 15 abr. 2005. Suplemento.

VAN DIJK, T. A. Ideología y discurso. Barcelona: Ariel, 2003

VERÓN, E. La palabra adversativa. In: .et al. El discurso político. Lenguajes y acontecimientos. Buenos Aires: Edicial, 1987.

WHITE, H. El contenido de la forma. Barcelona: Paidós, 1992.

\section{Notas}

1 Este trabajo presenta elaboraciones parciales en el marco de la producción de la tesis doctoral de la autora.

2 Una revisión del debate teórico sobre definiciones de la violencia puede leerse en Perelman(2007).

3 'La teoría de 'los excesos', deriva en el establecimiento de ciertas unidades de medida imprecisas y ambiguas basadas en los argumentos del uso 'razonable' (y por tanto legal) de la fuerzay una frontera más allá de la cual éste se torna 'excesivo', y en consecuencia abusiva e ilegal [...] Sin embargo, esta distinción entre usos 'razonables' y 'excesivos' resulta equívoca por dos razones. Primero, por su vaguedady amplitud, dado que nunca se establecen en forma explícita los parámetros utilizados para definirla, y en segundo término, porque pone todo el énfasis en la necesidad del uso de la violencia, dejando en penumbras aquellos aspectos que muestran las numerosas circunstancias en que el uso de la violencia no era necesaria" (MARTÍNEZ;EILBAUM, 1999,p. 8).

4 A partir de la lectura de una primera versión de este trabajo, la antropóloga María Josefina Martínez destacó la ausencia del termino 'piedad' en la escala de violencia que tiene su tope en la crueldad. Así como la violencia policial puede ascender (sobrerealizarse) hasta la crueldad, no registramos descripciones de hechos en los que un funcionario de seguridad descienda su violencia hacia la piedad. La asimetría del par conceptual piedad-crueldad en la escala de violencia puede tomarse como una pista para reflexionar acerca de lo que habitualmente se considera como 'grado cero' del uso de la violencia policial.

5 Debemos insistir en que esto último parece valido para la definición de violencia supuesta en discursos que abordan el tema de la violencia en relación con situaciones institucionales, policiales, políticas o públicas. A priori, suponemos que en discursos sobre la violencia 'doméstica' o 'familiar', la noción de violencia supuesta no comparte los rasgos de instrumentalidad que señalamos, sino que aparece abarcando otros sentidos cercanos a lo pasional, lo emocional, etc. Incluso, podemos aventurar que la escala se encuentra invertida: cuando se narran hechos de violencia que ocurren en el 'espacio privado' lo naturalizado es la violencia irracional y lo que se condena como cruel es cualquier rasgo de frialdad o violencia instrumental (como cuando un cónyuge mata a otro para cobrar un seguro o una herencia).

6 Los organismos de derechos humanos trabajan permanentemente sobre la tensión entre el caso y los patrones generales de las prácticas de violencia estatal. La estrategia del 'leading case' que propone como táctica el litigio en torno de un caso 'paradigmático' para alcanzar estándares generalizables, se encuentrajusto en un punto de articulación, en la intención de capitalizar hacia lo general, la atención que puede alcanzarse sobre lo particular. Esta táctica exige un cuidadoso uso del lenguaje para que lo particular se construya como paradigmático y no como excepcional.

\section{Marcela Perelman}

Doctoranda en Ciencias Sociales en la Facultad de Ciencias Sociales, Universidad de Buenos Aires (UBA)

Directora de doctorado: Antropóloga María Josefina Martínez

Co-director: Dr. Pablo Alabarces

UBA - Facultad de Ciencias Sociales

Sede Marcelo T. de Alvear

Marcelo T. de Alvear, 2230

(1122) Buenos Aires - Argentina 